\title{
Research on the Coupling Coordinated Development of New Urbanization and Finance
}

\author{
Bing Yang $^{1}{\text { Chenggang } \mathrm{Li}^{1}}^{1}$ Cong Luo $^{2}$ Li Dong $^{1} \mathrm{Xin} \mathrm{He}^{1}$ \\ ${ }^{1}$ School of Finance, Guizhou University of Finance and Economics, Guiyang, 550025, P. \\ R. China \\ ${ }^{2}$ Experimental Teaching Department, Guizhou University of Finance and Economics, \\ Guiyang, 550025, P. R. China
}

\begin{abstract}
Using the data of 31 provinces, municipalities and autonomous regions in China from 2010 to 2015, this paper utilizes the Principal Component Analysis method and coupling coordination model to empirially analysis the coupling coordinated development of urbanization and finance. The empircal results show that, the most average values of the comprehensive evaluation index of the urbanization of China's provinces, municipalities and autonomous regions fluctuate between 0.2 and 0.5 , and the the most average values of the comprehensive evaluation index of the finance fluctuate between 0.25 and 0.5 ; the average coupling degree of 18 provinces, municipalities or autonomous regions are in a high coupling degree, but the average coupling coordination degree of urbanization and financial are low coordination. It indicates that there is a deviation in the development of urbanization and finance in most area in China, and the two don't show synchronous development.
\end{abstract}

\section{Keywords}

Urbanization; Finance; Principal Component Analysis; Coupling coordination model

\section{新型城镇化与金融耦合协调发展研究}

\author{
杨兵 ${ }^{1}$ 李成刚 ${ }^{1}$ 罗聪 ${ }^{2}$ 董礼 ${ }^{1}$ 何欣 ${ }^{1}$ \\ 1 贵州财经大学金融学院, 贵州 贵阳, 550025, 中国 \\ 2 贵州财经大学实验教学部，贵州 贵阳, 550025, 中国
}

\begin{abstract}
摘要：本文采用我国 31 个省、市、自治区 2010-2015 年的相关数据, 利用主成分分析法和耦 合协调度模型，实证分析了我国新型城镇化与金融的耦合协调发展。实证结果表明，各省、 直辖市、自治区新型城镇化综合评价指数的平均值大多数在 $0.2-0.5$ 之间波动, 金融综合评 价指数的平均值大多数地区在 $0.25-0.5$ 左右; 各省、直辖市、自治区平均耦合度有 18 个地 区达到高度耦合，但是新型城镇化和金融的平均耦合协调度大部分都是低度协调，说明我国 大部分地区在新型城镇化和金融的发展方面都存在着偏差，两者没有呈现同步发展。
\end{abstract}

关键词：新型城镇化；金融；因子分析 ; 耦合模型 


\section{1. 引言}

为了促进我国经济更好更快地发 展, 我国在《国家城镇化规划(2014-2020 年)》提出了全面推进城镇化建设的目标, 明确了未来城镇化建设的发展方向。城 镇化建设必须围绕适用、经济、绿色、 美观方针，并且强调建设尊重自然、顺 应自然和保护自然的资源节约型和环 境友好型的城镇化。要走城镇化发展的 道路，就必须充分发挥金融的支持作用。 城镇化的发展需要大量的资金投入，离 不开金融支持，金融发展为城镇化建设 提供资金支持，所以必须建立一个完善 的金融系统以满足城镇化的资金需求。 如何协调城镇化和金融的发展是目前 急需解决的问题之一。因此, 研究城镇 化和金融耦合协调发展能够为我国城 镇化建设提供参考依据, 具有重要的现 实意义。

\section{2. 文献综述}

由于城镇化的飞速发展, 国内学者 也开始关注城镇化与金融之间的关系， 并对城镇化和金融的关系进行了大量 的研究, 取得了丰硕的研究成果。吴旭 晓（2013）[1]以 1994 年到 2011 年河南 省的数据为研究对象, 对 1994 年到 2011 年期间内河南省金融与城镇化耦 合发展趋势进行研究, 研究表明河南省 金融与城镇化之间的耦合关系呈现波 动式下滑。郭娜 (2013) [2]对 1996 年到 2013 年时间段内我国银行业金融支持 和城镇化的因果关系和协调程度进行 了实证分析，结果发现我国银行业金融 支持和城镇化之间因果联系大多是协 调程度不足。刘萌等 (2014) [3]分析了 我国城市土地投入产出效率与城镇化 之间的耦合协调状态, 得出在我国城市 土地投入产出效率与城镇化率间的耦 合关系相对较低, 并且在空间上中西部 有较大的差异。俞思静和徐维祥 (2016)
[4]以浙江省 2004 年至 2014 年的数据为 样本, 分析了浙江省金融产业集聚和新 型城镇化耦合协调关系在时空分异上 的差异，分析结果表明浙江省各市之间 的耦合协调度呈现逐年上升趋势, 并且 在空间分布上呈线的是板块化结构。李 媛媛和董鹏（2016） ${ }^{[5]}$ 采用面板分位数 回归模型研究了我国各省市自治区从 2005 年到 2014 年金融生态与新型城镇 化质量之间的关系, 研究表明我国各地 区金融生态与新型城镇化质量之间呈 现明显的差异。唐未兵和唐谭岭 (2017) [6]利用 2005 年到 2014 年我国中部六省 市数据, 研究了新型城镇化和金融支持 之间的耦合协调关系, 研究表明目前我 国中部六省市新型城镇化和金融支持 之间的耦合协调处于中度协调。

\section{3. 新型城镇化与金融综合体系构建}

\section{1. 新型城镇化综合体系的构建}

\subsection{1 数据来源和指标选择}

本文选取 2010-2015 年全国各省、 直辖市及自治区的面板数据。数据来源 于 2011-2016 年各省、直辖市及自治区 的《统计年鉴》、《中国金融年鉴》、

《中国财政年鉴》、《中国农村统计年 鉴》、中国国家统计局网站以及各省、 直辖市和自治区的统计局网站。

对于新型城镇化的研究, 本文借鉴 吴旭晓（2013） [1]，刘萌等（2014） [3], 唐未兵和唐谭岭（2017）等研究, 选 择指标包括了人口新型城镇化、经济新 型城镇化、社会新型城镇化、空间新型 城镇化和环境新型城镇化等五个方面, 遵循科学性、可测性、系统性和可获取 性等原则, 构建出 5 个方面的新型城镇 化指标评价体系。

\subsection{2 综合评价方法}

\subsubsection{1 主成分提取}


对于综合体系构建本文采用主成 分分析法对所选因子提取主成分因子, 再通过因子分析法计算综合得分, 即综 合评价指数。运用因子分析法之前, 首 先检验所选择指标是否合适做因子分 析，根据检验 $\mathrm{KMO}$ 的值为 0.604 , Bartlett 球形检验的卡方分布值为 2785.511 , 对应的 $\mathrm{p}$ 值为 0.000 , 小于 0.05 。因此, 各新型城镇化指标变量满 足因子分析的条件，可以进行因子分析。

采取主成分因子分析法对所有因 子提取主成分因子，计算得到各主成分 因子的特征值和贡献率可知, 提出 4 个 主成分因子, 分别记作为; F1、F2、F3 和 F4。它们分别可以解释原始变量 $33.654 \%$ 、15.209\%、14.181\%和 $8.762 \%$ 的信息。

\subsubsection{2 计算主成分得分}

根据所提取的 4 个主成分, 运用 SPSS 23 软件计算出主成分载荷矩阵, 根据主成分载荷矩阵, 新型城镇化综合 得分计算式如 (2) 所示。

$$
\begin{aligned}
& Y=0.29496 * S F_{1}+0.15295 * S F_{2} \\
& +0.15073 * S F_{3}+0.11943 * S F_{4}
\end{aligned}
$$

通过综合得分计算出我国 31 个省、 直辖市和自治区新型城镇化的综合指 数, 借鉴蒋桂娟等 (2012) [13]在林分结 构与水源涵养功能耦合关系研究中的 转换方法, 并加以改进, 转化公式如下:

$$
U_{1}=\frac{F_{i}-F_{\text {min }}}{F_{\text {mas }}-F_{\text {min }}}
$$

以式（3）计算出 2010 至 2015 年我国 新型城镇化的综合得分即新型城镇化 综合评价指数。对我国各省市自治区 2010 年到 2015 年的新型城镇化综合评 价指数求平均值, 并对各省、直辖市、 自治区的平均综合评价指数进行排名, 如图 1 所示。

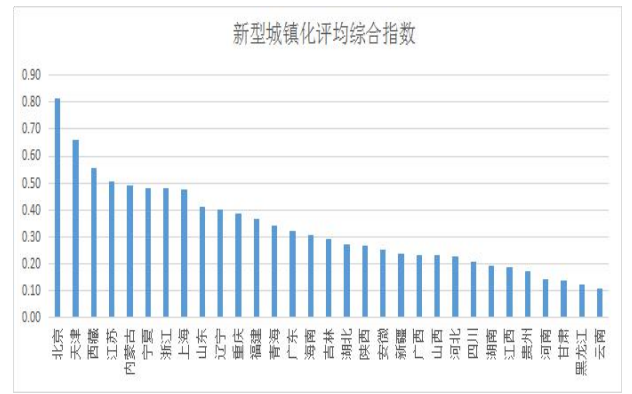

图 1 新型城镇化平均综合指数

由图 1 可知, 我国 2010 到 2015 年 各省、直辖市、自治区新型城镇化综合 评价指数的平均值大多数在 0.2-0.5 左 右波动。其中, 新型城镇化平均综合指 数最高的是北京, 综合评价指数为 0.82 , 北京是我国经济、政治的中心, 新型城 镇化水平远远高于我国其它省、市、自 治区。其次是天津, 综合评价指数为 0.66, 天津是我国环渤海地区经济中心, 经济发达, 海陆交通都便利, 因此新型 城镇化水平也是远远高于其它地区。新 型城镇化综合评价指数最低的是云南, 为 0.11 , 由于云南地处我国西南高原地 区, 交通不便, 经济落后, 新型城镇化 严重地落后于我国中东部沿海地区。

\section{2. 金融综合体系构建}

\subsection{1 指标选择}

对于金融综合指标体系, 本文选择 金融规模, 金融效率指和金融结构来作 为金融发展的指标体系。

\subsection{2 综合评价方法}

\subsubsection{1 主成分提取}

首先检验所选择指标是否合适做 因子分析。检验结果表明, KMO 的值 为 0.65 。Bartlett 球形检验的卡方分布值 为 1171.73 , 对应的 $\mathrm{p}$ 值为 0.000 , 小于 0.05 。因此, 在 0.05 的显著性水平下, 各金融体系指标变量满足因子分析的 条件, 可以进行因子分析。 
采取主成分因子分析法对所有因 子提取主成分因子，计算得到各主成分 因子的特征值、贡献率可提出三个主成 份因子分别为 F1、F2 和 F3, 它们分别 可以解释原始变量 $50.68 \%$ 、 $16.52 \%$ 和 $13.95 \%$ 的信息。

\subsubsection{2 计算主成分得分}

根据所提取的 3 个主成分, 运用 SPSS 23 软件计算出主成分载荷矩阵, 金融体系综合得分计算式如下所示: $Y=0.47856 * S F_{1}+0.18026 * S F_{2}$ $+0.15264 * \mathrm{SF}_{3}$

通过综合得分计算出我国 31 个省、 市、自治区金融体系的综合指数，再采 用式 (5) 计算出 2010-2015 年我国金融 的综合得分即金融体系综合评价指数。 对我国各省、直辖市和自治区 2010 到 2015 年的金融综合评价指数求平均值, 并对各省、直辖市、自治区的平均综合 评价指数进行排名, 如图 2 所示。

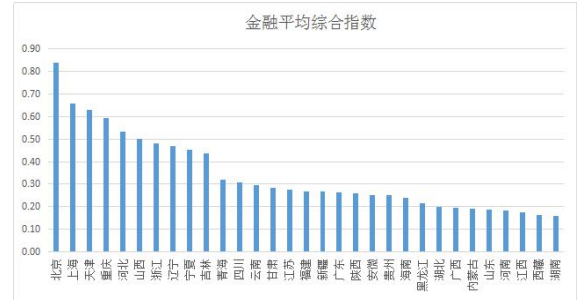

图 2 金融的平均综合评价指数

由图 2 可知, 我国各省、直辖市、 自治区金融综合评价指数的平均值大 多数地区在 $0.25-0.5$ 左右。其中, 金融 平均综合指数最高的是北京, 其综合评 价指数为 0.84 。北京市作为我国经济、 政治文化的中心，是我国金融最发达的 城市之一。其次是上海, 其综合评价指 数为 0.66 。上海市作为我国经济、金融 最发达城市之一, 更是亚洲金融的中心, 上海的金融发展速度远远快于其它省、 直辖市、自治区。金融综合评价指数最 低的是西藏和湖南, 仅为 0.16 。西藏主 要是由于地处青藏高原, 经济落后, 导
致金融发展水平低。湖南是我国的农业 大省, 主要发展农业为主, 金融业的发 展相对其他地区相对比较落后。

\section{4. 新型城镇化与金融的耦合协调度 实证分析}

\section{1. 耦合度模型}

本文研究新型城镇化综合指数 (U1) 和金融综合指数 (U2) 之间的耦合关系, 借鉴龙肖毅和张咏梅（2016） [8]、宋祺 佼和吕斌 (2017) ${ }^{[9]}$ 的耦合度模型研究, 构建新型城镇化与金融耦合度模型如 下:

$$
C=\left\{\frac{U_{1} \times U_{2}}{\left(U_{1}+U_{2}\right)^{2}}\right\}^{1 / 2}
$$

其中, $\mathrm{C}$ 是指新型城镇化综合指数 和金融综合指数的耦合度, $\mathrm{C}$ 的取值位 于 $[0,1]$ 之间。当 $\mathrm{C}=1$ 时, 说明新型城 镇化和金融之间耦合度最大, 新型城镇 化和金融之间彼此达到良性共振耦合; $\mathrm{C}=0$ 时, 耦合度极小, 新型城镇化和金 融之间要素处于无关状态。U1 和 U2 分 别代表是新型城镇化综合指数和金融 综合指数。耦合度虽然可以反映新型城 镇化和金融互相作用程度，但不足以完 全反映出它们之间的协调程度, 因为每 个地区的发展都会存在动态的特征。因 此，本文基于耦合度模型之上建立耦合 协调度的模型, 可以更好地评判新型城 镇化和金融相互之间协调发展的程度。 本文构建耦合协调度模型如下:

$$
\left\{\begin{array}{c}
D=\sqrt{C^{*} T} \\
T=\alpha \times U_{1}+\beta \times U_{2}
\end{array}\right.
$$

其中, $\mathrm{D}$ 为新型城镇化和金融耦合 协调度, 取值在 0-1 之间; $\mathrm{C}$ 为新型城 镇化和金融耦合度; $\mathrm{T}$ 为新型城镇化和 金融的耦合协调指数, 反映二者的整体 发展水平对协调度的贡献; 系数 $\alpha+\beta=1$, 由于本文的耦合分析将新 型城镇化和金融视为同等重要, 故 
$\alpha=\beta=\frac{1}{2}$ 。

\section{2. 耦合度和耦合协调度分类等级}

根据新型城镇化和金融的相互耦 合强弱, 并参考俞思静和徐维祥 (2016) [4]、唐未兵和唐谭岭（2017） [6]等文献, 对新型城镇化和金融的耦合度和耦合 协调度等级的划分, $0<\mathrm{C} \leq 0.4$ 为低度耦 合和低度协调, $0.4<\mathrm{C} \leq 0.48$ 为中度耦 合和中度协调, $0.48<\mathrm{C} \leq 0.7$ 为高度耦 合和高度协调, $0.7<\mathrm{C} \leq 1.0$ 为极度耦合 和极度协调。

\section{3. 耦合度和耦合协调度的测算}

通过对新型城镇化和金融综合体 系的构建，运用主成分分析法计算出新 型城镇化和金融的综合指数，采用耦合 模型计算出 2010 年到 2015 年新型城镇 化综合指数和金融综合指数的耦合度 与耦合协调度, 并对我国各省市自治区 2010 到 2015 年的耦合度和耦合协调度 取平均值, 根据耦合协调度的等级划分, 对我国各省市自治区 2010 到 2015 年的 平均耦合度和耦合协调度进行分类, 运 用软件对我国各省、直辖市、自治区 2010 到 2015 年新型城镇化和农村金融 的平均耦合度做出趋势图, 如图 3 所示。

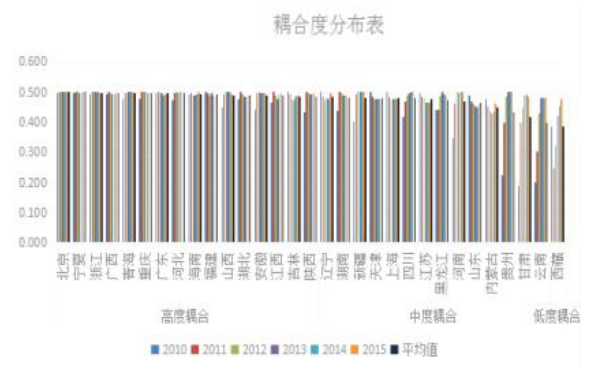

图 3 耦合度分布图

由图 3 可知, 我国各省、直辖市、 自治区 2010 到 2015 年新型城镇化和金 融的平均耦合度有 18 个地区达到高度 耦合, 分别是北京、宁夏、浙江、上海
等地区, 而且北京地区的耦合度相对比 较平稳, 高于宁夏和浙江等地。从高度 耦合的地区来看，新型城镇化和金融高 度耦合最高的地区是经济非常发达的 北京、上海和浙江。不管是新型城镇化 的发展还是金融的发展，都和经济发展 息息相关。因此, 新型城镇化和金融的 耦合程度以体现了一个地区经济的发 展程度。新型城镇化和金融中度耦合地 区包含辽宁、湖南和江苏等 12 个地区, 可以看出新型城镇化和农村金融中度 耦合地区都是经济相对比较发达, 但是 与北京、上海和浙江等地区还存在差别。 中度耦合地区贵州、甘肃和云南等地区 的耦合对从 2010 到 2015 年都是呈线性 增长, 说明这几个地区新型城镇化和金 融之间的耦合度呈快速上升的趋势。新 型城镇化和金融低度耦合地区只有西 藏, 西藏地处我国高原地区, 经济相对 于我国东部城市来说相对落后。因此, 新型城镇化和金融的发展水平都相对 较低, 但从 2010 年开始耦合度也呈上 升趋势。

运用软件对我国各省、直辖市、自 治区 2010 到 2015 年新型城镇化和农村 金融的平均耦合协调度做出趋势图, 如 图 4 所示。

\section{䁬合协调度分布表}

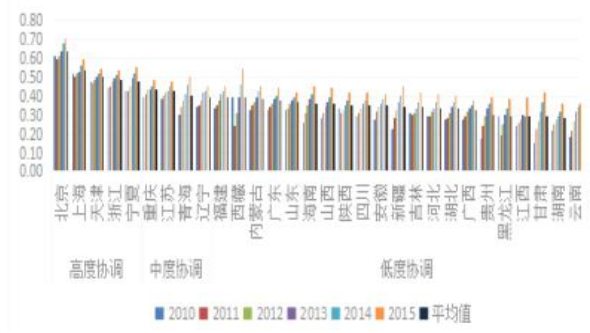

图 4 耦合协调度分布图

由图 4 可知, 我国各省、直辖市、 自治区 2010 到 2015 年新型城镇化和金 融的平均耦合协调度大部分都是低度 协调, 说明我国大部分地区在新型城镇 化和金融的发展方面都存在着偏差, 两 
者并没有呈现同步协调发展。其中, 高 度协调的地区只有上海、北京、天津、 浙江和宁夏等 5 个地区，耦合协调度的 平均值分别为 $0.64 、 0.54 、 0.50 、 0.49$ 和 0.48 , 从 2010 年开始耦合协调度都 呈线性增长, 说明这些地区新型城镇化 和金融发展速度较快并协调性较好。中 度协调的地区包括重庆、江苏、青海和 辽宁等 4 个省、直辖市、自治区。低度 协调地区包括山西、广东等 22 个省、 直辖市、自治区。从耦合协调度来看, 在我国经济发达城市和经济落后地区 有明显的差别: 经济越发达的地区, 新 型城镇化和金融的耦合协调度越高, 经 济越落后的地区, 新型城镇化和金融的 耦合协调度越低。

\section{5. 结论}

本文选取我国 2010 到 2015 年 31 个省、直辖市、自治区的面板数据, 运 用主成分因子分析法构建了新型城镇 化和金融综合评价体系, 采用耦合度模 型和耦合协调度模型, 实证分析了新型 城镇化综合指数和金融支撑综合指数 的耦合度与耦合协调度。根据本文的研 究, 本文得到如下结论:

第二，我国各省、直辖市、自治区 新型城镇化综合评价指数的平均值大 多数在 0.2-0.5 左右波动。其中, 新型城 镇化平均综合指数最高的是北京, 最低 的是云南。各省、直辖市、自治区金融 综合评价指数的平均值大多数地区在 0.25-0.5 左右。其中，金融平均综合指 数最高的是北京, 最低的是西藏和湖南。

第三，我国各省、直辖市、自治区 新型城镇化和金融的平均耦合度有 18 个地区达到高度耦合。新型城镇化和金 融中度耦合地区包含辽宁、湖南和江苏 等 12 个地区。新型城镇化和金融低度 耦合地区只有西藏。

\section{参考文献}

[1] 吴旭晓. 后发地区金融发展与城镇 化耦合协调发展研究——以河南 省为例 $[\mathrm{J}]$. 安徽商贸职业技术学 院学报, 2013, 12(2): 37-42.

[2] 郭娜. 银行业金融支持与城镇化协 调发展一一基于系统耦合视角的 实证分析 $[\mathrm{J}]$. 金融教学与研究, 2013, (4): 16-19.

[3] 刘萌, 冯长春, 曹广忠。中国城市 土地投入产出效率与城镇化水平 的耦合关系一对 286 个地级及以 上城市行政单元的分析 $[\mathrm{J}]$. 中国 土地科学, 2014, 28(5): 51-57.

[4] 俞思静, 徐维祥. 金融产业集聚与 新型城镇化耦合协调关系时空分 异研究——以江浙沪为例 $[\mathrm{J}]$. 华 东经济管理, 2016, 30(2): 27-33.

[5] 李媛媛, 董鹏. 金融生态与新型城 镇化质量一基于面板分位数回 归模型的实证检验 [J].河北大学学 报(哲学社会科学版), 2016, 41(5): 103-110.

[6] 唐未兵, 唐谭岭. 中部地区新型城 镇化和金融支持的耦合作用研究 [J]. 中国软科学，2017，(3): 140-151.

[7] 蒋桂娟, 郑小贤, 宁杨翠. 林分结 构与水源涵养功能耦合关系研究 以北京八达岭林场为例 $[\mathrm{J}]$. 西北林学院学报, 2012, 27(2): 175-179.

[8] 龙肖毅, 张咏梅. 乡村旅游产业与 农村经济发展交互耦合协调发展 的实证研究 $[\mathrm{J}]$. 西南师范大学学 报 (自然科学版)，2016，41(5): 104-107.

[9] 宋祺佼, 吕斌. 城市低碳发展与新 型城镇化耦合协调研究——中 国低碳试点城市为例 $[\mathrm{J}]$. 北京理 工大学学报(社会科学版), 2017, 19(2): 20-27. 